\title{
Avaliação da influência da poda no desempenho da máquina de colheita em pomares superintensivos de amendoeira
}

\author{
António B. Dias' ${ }^{1}$ J. Reis' ${ }^{2}$, J. Rebola, ${ }^{2}$ J. Falcão ${ }^{2}$, Anacleto Pinheiro ${ }^{1}$, José O. Peça ${ }^{1}$ \\ 1 Instituto de Ciências Agrárias e Ambientais Mediterrânicas (ICAAM)/Departamento de Engenharia \\ Rural da Universidade de Évora. Núcleo da Mitra, Apartado 94, 7002-554 Évora, Portugal; \\ adias@uevora.pt; jmop@uevora.pt; pinheiro@uevora.pt \\ 2 Torre das Figueiras Sociedade Agrícola Lda. Herdade da Torre das Figueiras, Apartado 23, 7450 - 999 \\ Monforte
}

Resumo: O sucesso da tecnologia de colheita dos olivais superintensivos terá contribuído para a implantação de pomares superintensivos de amendoeira. Nestes pomares é necessário garantir que a dimensão da copa se adeque às dimensões da máquina de colheita para minimizar as perdas de amêndoa e os danos nas árvores. Para aumentar o conhecimento sobre esta tecnologia, estabeleceu-se num pomar comercial, um ensaio para avaliar o efeito da poda na produção de amêndoa e no desempenho da máquina de colheita. O pomar foi plantado em setembro de 2014, na Herdade da Torre das Figueiras - Monforte - Portalegre - Portugal (39o 04’ N; 07을’ W), com a orientação Este-Oeste, entrelinha de $5 \mathrm{~m}$ e 1,5 m de afastamento entre as árvores na linha. Definiram-se os seguintes tratamentos: T0 - poda de verão: corte horizontal da copa e corte lateral em cada uma das faces, em 2015 e 2017. Em 2015, os cortes laterais foram executados em julho e os cortes horizontais em julho e em setembro. Em setembro de 2017, após a colheita, realizou-se corte lateral em cada uma das faces da copa e corte horizontal da copa. Em Julho de 2016 eliminaram-se manualmente ramos excessivamente desenvolvidos para a entrelinha. Poda de inverno: em 2016, poda manual para eliminar ramos vigorosos; em 2017, corte horizontal da copa seguido de poda manual para melhorar a exposição solar no interior da sebe; T1 - sem intervenções de poda em 2015, 2016 e 2017; T2 - poda de verão: corte lateral em cada uma das faces da copa, realizado em julho de 2015; corte lateral em cada uma das faces da copa e corte horizontal em setembro de 2017, após a colheita; T3 - poda de verão: corte horizontal da copa e corte lateral em cada uma das faces, em 2015 e 2017. Em 2015, os cortes laterais foram executados em julho e os cortes horizontais em julho e em setembro. Em setembro de 2017, após a colheita, efectuou-se corte lateral em cada uma das faces da copa e corte horizontal da copa. Em 2018, em todos os tratamentos, procedeu-se a uma poda manual de inverno para eliminar ramos vigorosos excessivamente desenvolvidos para a entrelinha. Em 2017, selecionaram-se aleatoriamente 3 blocos de 10 árvores em cada linha para monitorizar a altura da árvore e a largura da copa na perpendicular à linha. Em 2017 e 2018 procedeu-se à colheita de cada linha, registando a massa de amêndoa colhida e o tempo de trabalho, tendo-se avaliado por amostragem as perdas de amêndoa para o solo. Verificaram-se diferenças na produção de amêndoa entre os anos, bem como diferenças significativas entre os tratamentos em 2018. Houve uma diminuição de perdas de amêndoa para o solo de 2017 para 2018. Em 2018 o tratamento 1 registou uma percentagem de perdas significativamente superior aos outros tratamentos.

Palavras chave: poda mecânica; fruteiras; produção; colheita contínua 


\section{CONGRESO IBÉRICO DE AGROINGENIERÍA \\ X CONGRESSO IBÉRICO DE AGROENGENHARIA \\ 3 - 6 septiembre 2019, Huesca - España}

\section{Introdução}

Após a generalização dos olivais superintensivos, tem-se assistido à instalação de pomares superintensivos de amendoeira. Este sistema de condução tem como objectivo permitir a redução dos custos de colheita, visto que pode utilizar as mesmas máquinas de colheita contínua da vinha e do olival [3]. Este autor refere ainda que a opção por este tipo de plantação permite reduzir as necessidades de mão-de-obra para a plantação e para a poda, bem como a melhoria da entrada em produção, o incremento da produção e a redução da alternância produtiva e a melhoria da qualidade do miolo de amêndoa.

$\mathrm{Na}$ condução destes pomares existe a preocupação em garantir que a dimensão da copa se adeque às dimensões da máquina de colheita. Dever-se-á conduzir o pomar como uma sebe desorganizada, multieixo, na qual a largura de copa que não deve ultrapassar os 70-80 cm e os $2.75 \mathrm{~m}$ de altura [3]. O recurso à poda mecânica deverá ser efectuado desde o primeiro ano, quer com cortes laterais da copa, quer com corte horizontais na parte superior da mesma. As intervenções de poda manual deverão ser efectuadas apenas quando for necessário eliminar ramos secos e ramos muito vigorosos [3].

Atendendo ao facto de existirem poucas referências sobre a condução de pomares superintensivos de amendoeira, estabeleceu-se, num pomar comercial, um ensaio para avaliar o efeito das intervenções de poda na produção de amêndoa e na eficiência de recolha.

\section{Material e Métodos}

\subsection{Pomar}

O pomar foi plantado em setembro de 2014, na Herdade da Torre das Figueiras - Monforte

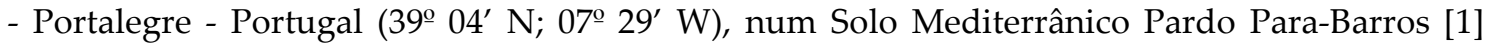
armado em camalhões, com entrelinha de $5 \mathrm{~m}$ e 1,5 $\mathrm{m}$ de afastamento entre as árvores na linha e as linhas numa orientação Este-Oeste. Foram utilizadas plantas com 6 meses de viveiro, provenientes da empresa Agromillora Catallana. Inicialmente as árvores foram tutoradas para garantir a formação em eixo central, procurando garantir um afastamento da base da copa ao solo de cerca de $0,5 \mathrm{~m}$.

O pomar dispõe de rega gota a gota, estimando-se em $1500 \mathrm{~m}^{3}$ a dotação anual de rega nos dois anos de ensaio.

Foram efectuados tratamentos fitossanitários para controlo da mancha ocre (Polystigma amygdalinum P.F. Cannon), do crivado (Stigmina carpophila), da moniliose (Monilinia Laxa Honey) e dos ácaros (Tetranychus urticae Koch and Panonychus ulmi Koch).

As infestantes foram controladas com herbicida na linha e com máquina de destroçar erva na entrelinha.

A fertilização foi efectuada através da rega e foliarmente, tendo sido aplicadas cerca de 30 unidades de azoto, 20 de fosforo e 40 de potássio.

O ensaio foi instalado na parcela com a cultivar 'Soleta', enxertada em rootpac 20 (Prunus besseyi $x$ Prunus cerasifera) (www.rootpac.com).

\subsection{Equipamentos}

As intervenções de poda mecânica de 2016, 2017 e 2018 foram realizadas com uma máquina de podar de discos R\&O (Reynolds \& Oliveira Ltd.) com uma barra de corte de 3,0m de largura (Figura 1), montada no carregador frontal de um tractor 4 WD com $97 \mathrm{~kW}$ (DIN) de potência máxima [2].

Em 2015, as intervenções de poda mecânica foram realizadas com um corta sebes portátil Sthill, accionado por motor de explosão (Figura 2).

Em 2017 e em 2018 utilizou-se uma máquina automotriz Gregoire G9.330 (Figura 3), na colheita da amêndoa. 


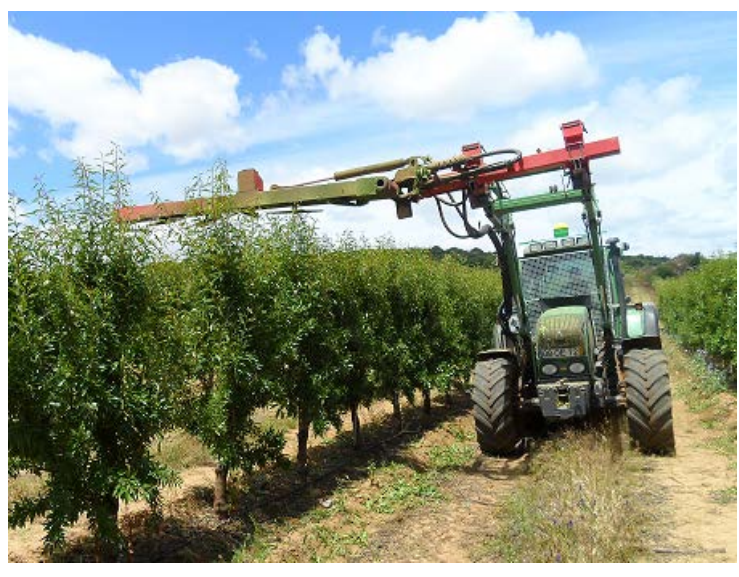

Figura 1. Máquina de podar montada em tractor, a efectuar poda de verão

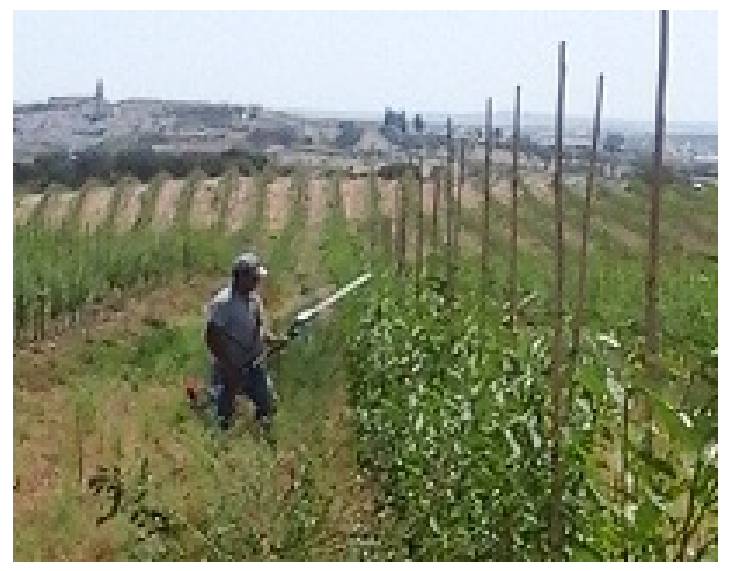

Figura 2. Corta sebes portátil Sthil

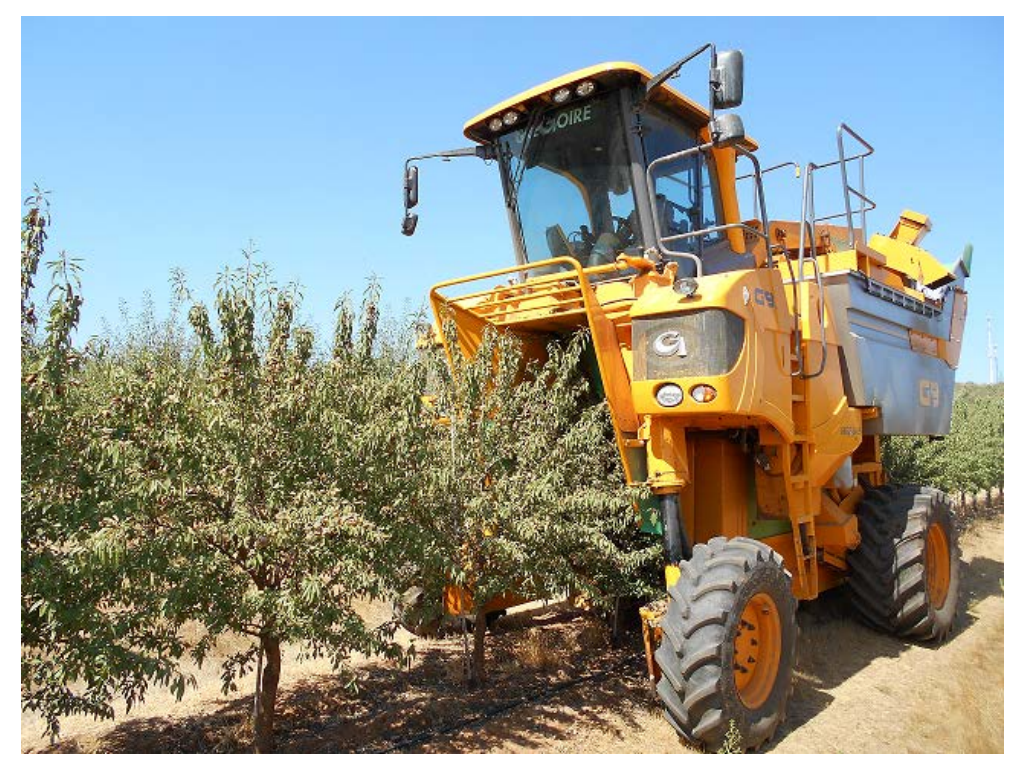

Figura 3. Máquina automotriz Gregoire G9.330 na colheita do ensaio em 2017

\subsection{Metodologia}

Na parcela com a cultivar 'Soleta' foram aleatoriamente selecionadas 12 linhas com 93 árvores. Definiram-se os seguintes tratamentos (Figura 4):

- T0 (Poda agricultor) - poda de verão: corte horizontal da copa ("topping") e corte lateral em cada uma das faces, em 2015, 2017 e 2018. Em 2015, os cortes laterais foram executados em julho e os cortes horizontais em julho e em setembro. Em Julho de 2016 eliminaram-se manualmente ramos excessivamente desenvolvidos para a entrelinha. Em setembro de 2017, após a colheita, realizou-se corte lateral em cada uma das faces da copa e corte horizontal da copa. Em junho de 2018 realizou-se corte lateral em cada uma das faces da copa e corte horizontal da copa. Poda de inverno: em 2016, poda manual para eliminar ramos vigorosos; em 2017, corte horizontal da copa seguido de poda manual para melhorar a exposição solar no interior da sebe;

- T1 - sem intervenções de poda em 2015, 2016 e 2017;

- T2 - poda de verão: corte lateral em cada uma das faces da copa, realizado em julho de 2015; corte lateral em cada uma das faces da copa e corte horizontal em setembro de 2017 e em setembro de 2018, após a colheita;

- T3 - poda de verão: corte horizontal da copa e corte lateral em cada uma das faces. Em 2015 , os cortes laterais foram executados em julho e os cortes horizontais em julho e em setembro. 


\section{CONGRESO IBÉRICO DE AGROINGENIERÍA \\ X CONGRESSO IBÉRICO DE AGROENGENHARIA \\ 3 - 6 septiembre 2019, Huesca - España}

Em setembro de 2017, após a colheita, efectuou-se corte lateral em cada uma das faces da copa e corte horizontal da copa. Em julho de 2018 efectuou-se corte lateral em cada uma das faces da copa e corte horizontal da copa.

Em 2018, em todos os tratamentos, procedeu-se a uma poda manual de inverno para eliminar ramos vigorosos excessivamente desenvolvidos para a entrelinha.

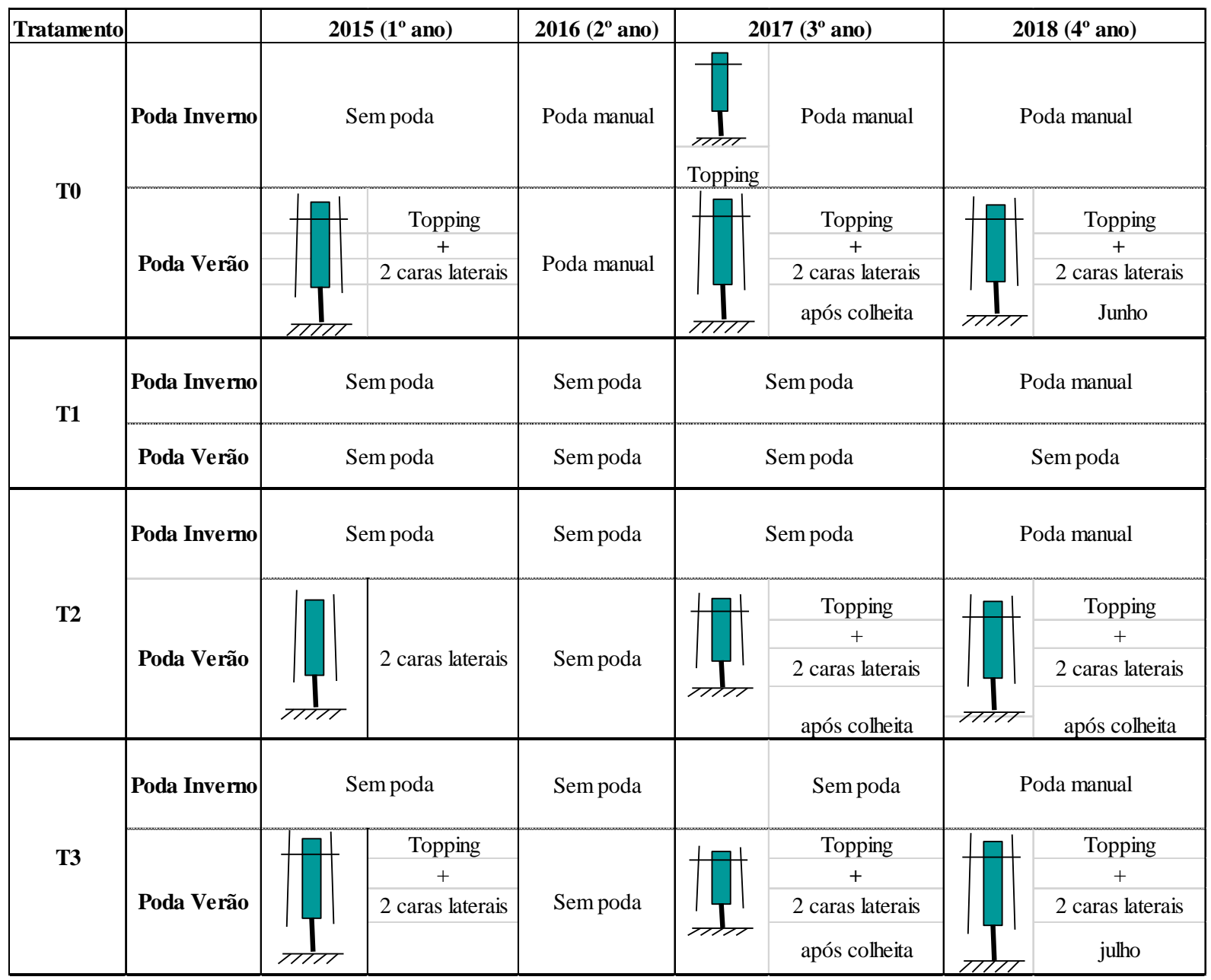

Figura 4. Sequência das intervenções de poda realizadas nos diferentes tratamentos desde a plantação

Em 2017, selecionaram-se aleatoriamente 3 blocos de 10 árvores em cada linha para monitorizar a altura da árvore, a distância da base da copa ao solo, a largura da copa na perpendicular à linha e as perdas de amêndoa para o solo.

Em 2017 e 2018 procedeu-se à colheita de cada linha, registando a massa de amêndoa colhida e o tempo de trabalho, tendo-se avaliado por amostragem as perdas de amêndoa para o solo.

Foi feita a análise de variância (ANOVA), utilizando o programa SPSS 24. Sempre que a análise de variância revelou diferenças significativas, foi feito o Teste de Separação Múltipla de Médias de Duncan para um nível de significância de 5\%. 


\section{Resultados e discussão}

\subsection{Altura das árvores}

Em relação à altura das árvores à colheita de 2017 (Figura 5), verificaram-se diferenças significativas entre os tratamentos $(\mathrm{P}<0.05)$. $\mathrm{O}$ tratamento $\mathrm{T} 2$ apresentava as árvores mais altas, as quais diferiam significativamente $(\mathrm{P} \leq 0.05)$ dos restantes tratamentos. $\mathrm{O}$ tratamento $\mathrm{T} 3$ apresentava as árvores mais baixas as quais diferiam significativamente $(\mathrm{P} \leq 0.05)$ dos outros tratamentos. Esta monitorização mostra que apesar do agricultor ter realizado um "topping" no inverno de 2017, no tratamento T0, durante a primavera houve emissão de lançamentos na parte superior da copa levando a que essas árvores tivessem uma altura que não diferia da registada nas árvores que estavam sem podar desde a plantação (tratamento T1).

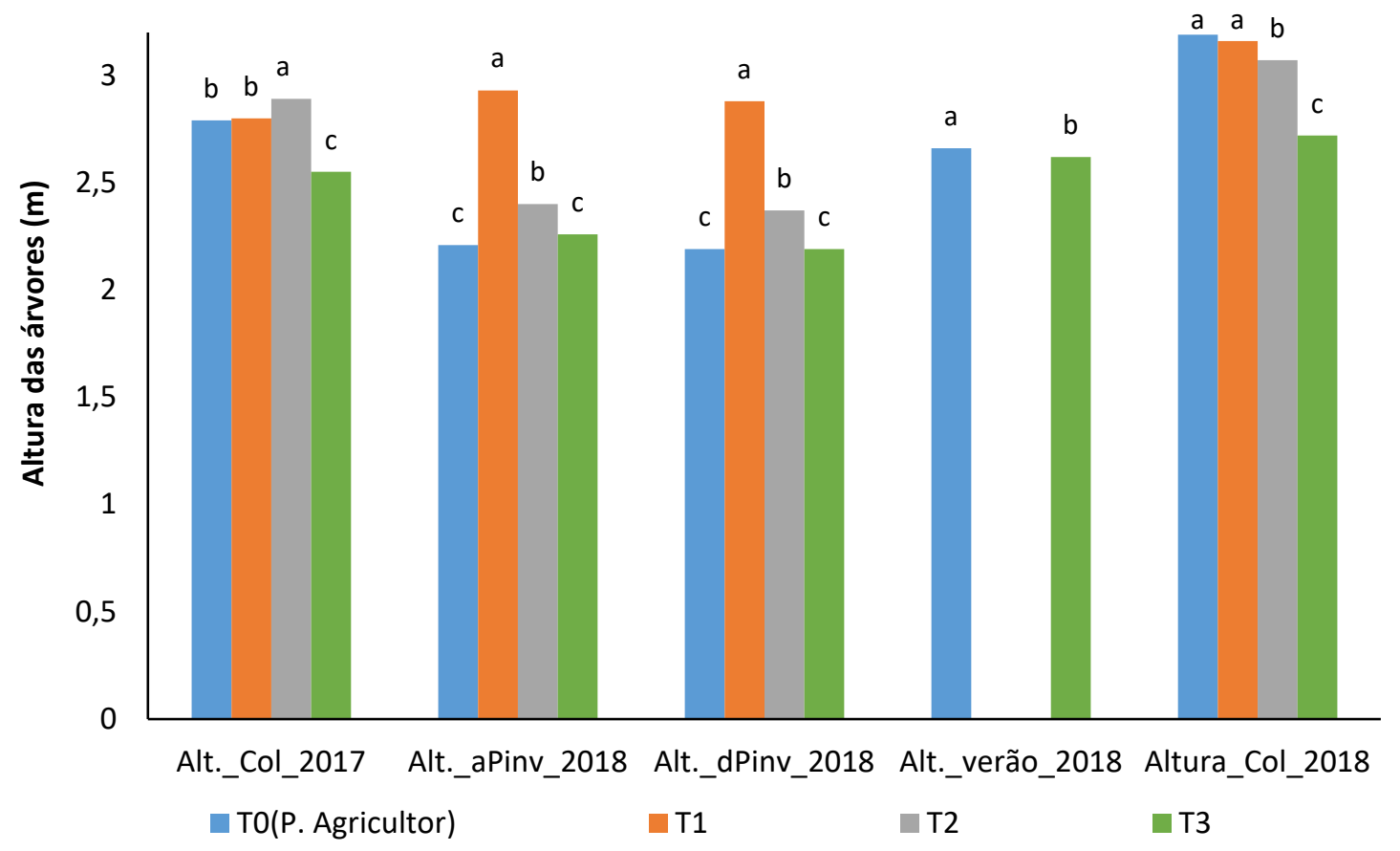

Legenda: Alt._Col_2017 - altura das árvores à colheita, em 2017; Alt._aPinv_2018 - altura das árvores antes da poda de inverno de 2018; Alt._dPinv_2018 - altura das árvores depois da poda de inverno de 2018; Alt._verão_2018 - altura das árvores depois da poda de verão de 2018; Alt._Col_2018 - altura das árvores à colheita, em 2018

Colunas acompanhadas de letras diferentes diferem significativamente entre si, segundo o teste de separação de médias de Duncan ( $\mathrm{P} \leq 0,05)$

Figura 5 - Altura média das árvores por tratamento.

A maior altura registada no tratamento T2 poderá estar associada aos cortes laterais da copa realizados em 2015, que levaram a que estas árvores tenham sido sempre mais altas (Dias et al, 2018). No caso do tratamento T3, a menor altura poderá ser consequência do "topping" realizado na fase inicial de desenvolvimento das árvores, levando a que estas tenham sido sempre mais baixas (Dias et al, 2018).

Antes da poda de inverno de 2018 registaram-se diferenças significativas $(\mathrm{P}<0.05)$ entre os tratamentos na altura das árvores. $\mathrm{O}$ tratamento $\mathrm{T} 1$ tinha as árvores mais altas as quais diferiam significativamente $(\mathrm{P} \leq 0.05)$ dos outros tratamentos. O "topping" pós colheita efectuado em 2017 reduziu a altura das árvores dos tratamentos T0, T2 e T3. Embora tenha havido a preocupação em efectuar o "topping" à mesma altura em todos os tratamentos, verifica-se (Figura 5) que o tratamento T2 tinha as árvores significativamente $(\mathrm{P} \leq 0.05)$ mais altas do que os tratamentos T0 e T3. Sendo o 


\section{CONGRESO IBÉRICO DE AGROINGENIERÍA \\ X CONGRESSO IBÉRICO DE AGROENGENHARIA \\ 3 - 6 septiembre 2019, Huesca - España}

controlo da altura de corte realizado pelo operador com o carregador frontal do tractor, poderá ter havido alguma alteração no seu posicionamento, originando as diferenças registadas.

Não se registaram diferenças consideráveis na altura das árvores, antes e depois da poda de inverno de 2018. Tal deve-se ao facto de na poda de inverno se ter efectuado poda manual em todos os tratamentos, para eliminar ramos vigorosos excessivamente desenvolvidos para a entrelinha, o que não teve praticamente nenhuma influência na altura das árvores. De referir que nos tratamentos T0, T2 e T3 as árvores tinham uma altura inferior à altura máxima da unidade de colheita $(2.6 \mathrm{~m})$ da máquina automotriz.

Após as intervenções de poda de verão verificaram-se diferenças significativas $(P<0.05)$ entre os tratamentos, com o tratamento $\mathrm{T} 0$ a registar os maiores valores. As diferenças registadas estão associadas à dificuldade em ajustar e manter a uniformidade da altura de corte. Nestes tratamentos as árvores ficaram com uma altura maior do que tinham após a poda de inverno e com valores próximos da altura máxima da unidade de colheita da máquina automotriz.

Em relação à altura das árvores à colheita de 2018 (Figura 5), verificaram-se diferenças significativas entre os tratamentos $(\mathrm{P}<0.05)$. O tratamento $\mathrm{T} 3$ apresentava as árvores mais baixas, as quais diferiam significativamente $(\mathrm{P} \leq 0.05)$ dos restantes tratamentos. Tal estará associado ao facto do "topping" de verão ter sido efectuado no final de julho de 2018 e de não ter havido emissão de novos lançamentos na parte superior da copa após esse corte, conforme se pretendia. No caso do tratamento T0, houve um aumento da altura das árvores desde a poda de verão até à colheita da amêndoa, não se registando diferenças significativas em relação ao tratamento 1 $(\mathrm{P} \leq 0.05)$. Embora os lançamentos emitidos após a poda de verão no tratamento T0 sejam ramos ladrões, que não têm fruta e são flexíveis, estes resultados indiciam que o "topping" de verão poderá estar a ser efectuado precocemente.

Salientar ainda que o tratamento T2 apresentava árvores com uma altura significativamente $(\mathrm{P} \leq 0.05)$ inferior ao tratamento 0. Os ramos que surgiram após o corte pós colheita de 2017 (tratamento T2) são ramos ladrões, flexíveis e sem fruta, o que poderá ser um bom indicador da mais valia desta solução para controlar a altura das árvores.

\subsection{Base da copa ao solo}

Na figura 6 mostra-se o resultado da monitorização do afastamento da base da copa ao solo para cada tratamento, em diferentes momentos. Deve referir-se que em 2015 e 2016 houve a preocupação em deixar todas as árvores com um afastamento da base da copa ao solo de cerca de $0,5 \mathrm{~m}$. Os resultados obtidos refletem essa uniformidade.

De realçar que após a poda de inverno de 2018 se verificaram diferenças significativas entre os tratamentos $(\mathrm{P}<0.05)$, com o tratamento $\mathrm{T} 1$ a registar o maior afastamento ao solo. Tendo havido uma intervenção de poda manual em todos os tratamentos, este resultado mostra que no tratamento T1 terão sido cortados mais ramos na base da copa, aumentando a seu afastamento ao solo. Trata-se de pequenas diferenças, que dependem da decisão do podador, baseadas apenas na observação visual.

Antes da colheita de 2018 verificaram-se diferenças significativas entre os tratamentos $(\mathrm{P}<0.05)$, com o tratamento T1 a registar o menor afastamento da base da copa ao solo. Neste tratamento os ramos das árvores tendem a ser mais compridos do que nos restantes devido ao facto das árvores terem estado sem podar desde a plantação até 2018 e de em 2018 a poda manual se ter baseado apenas em desramações. Tal leva a que estes ramos revelem uma maior tendência em fletir devido à produção que suportam, levando a que a sua extremidade se aproxime do solo.

Esta monitorização vem contribuir para confirmar a necessidade de manter um afastamento da base da copa ao solo de cerca de $0,5 \mathrm{~m}$. Ramos mais baixos podem ser quebrados pela máquina de colheita e a amêndoa que suportarem tenderá a perder-se para o solo, por ficarem ao nível das placas retráteis da interface máquina-tronco das árvores. 


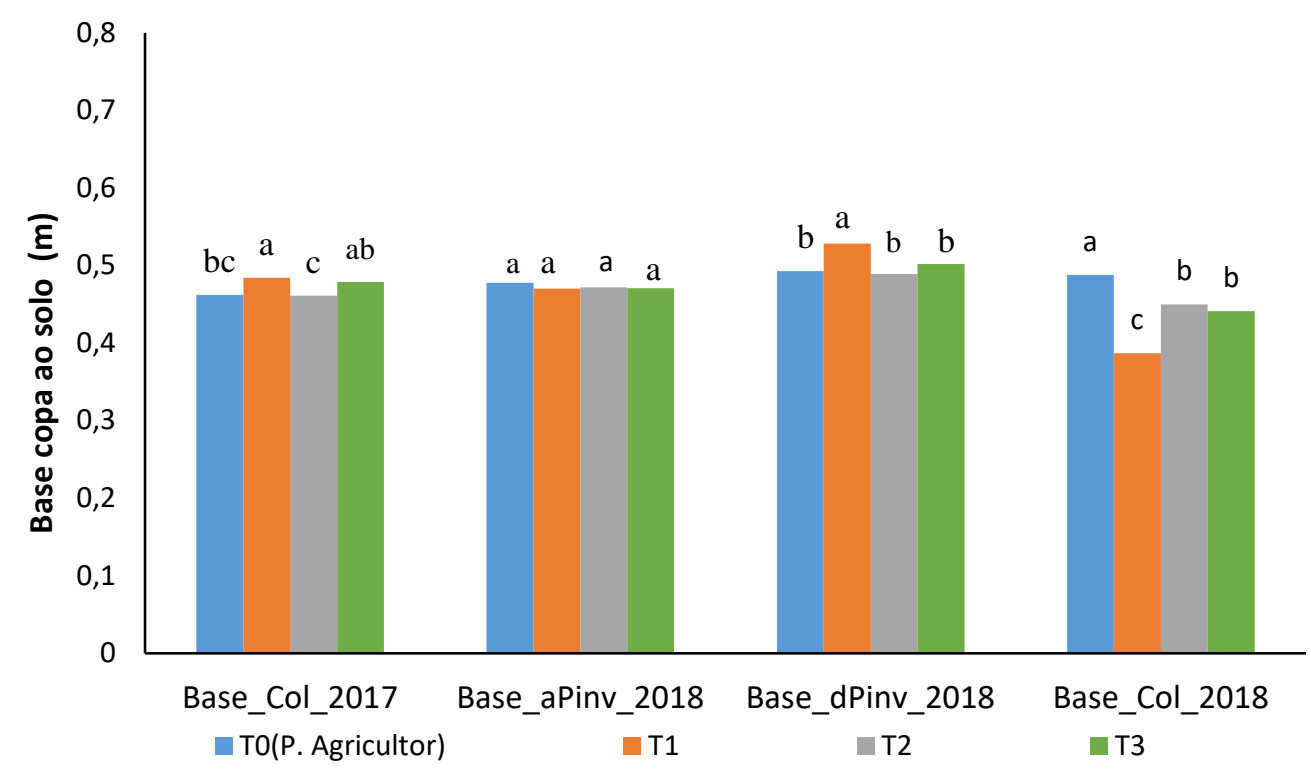

Legenda: Base._Col_2017 - base da copa à colheita, em 2017; Base_aPinv_2018 - base da copa antes da poda de inverno de 2018; Base_dPinv_2018 - base da copa depois da poda de inverno de 2018; Base_Col_2018 - base da copa à colheita, em 2018

Colunas acompanhadas de letras diferentes diferem significativamente entre si, segundo o teste de separação de médias de Duncan $(\mathrm{P} \leq 0,05)$

Figura 6. Afastamento da base da copa ao solo, em média, por tratamento.

\subsection{Largura de copa}

Na figura 7 mostra-se os resultados da monitorização da largura da copa. Antes da colheita de 2017 registaram-se diferenças significativas entre os tratamentos $(\mathrm{P}<0.05)$, tendo o tratamento $\mathrm{T} 1$ revelado uma largura de copa significativamente superior $(\mathrm{P} \leq 0.05)$ à dos restantes tratamentos. Estas diferenças devem-se ao facto de neste tratamento as árvores terem estado sem podar desde a plantação, enquanto no tratamento T0 houve intervenções de poda manual, quer em 2016, quer em 2017, que serviram para eliminar ramos excessivamente desenvolvidos para a entrelinha.

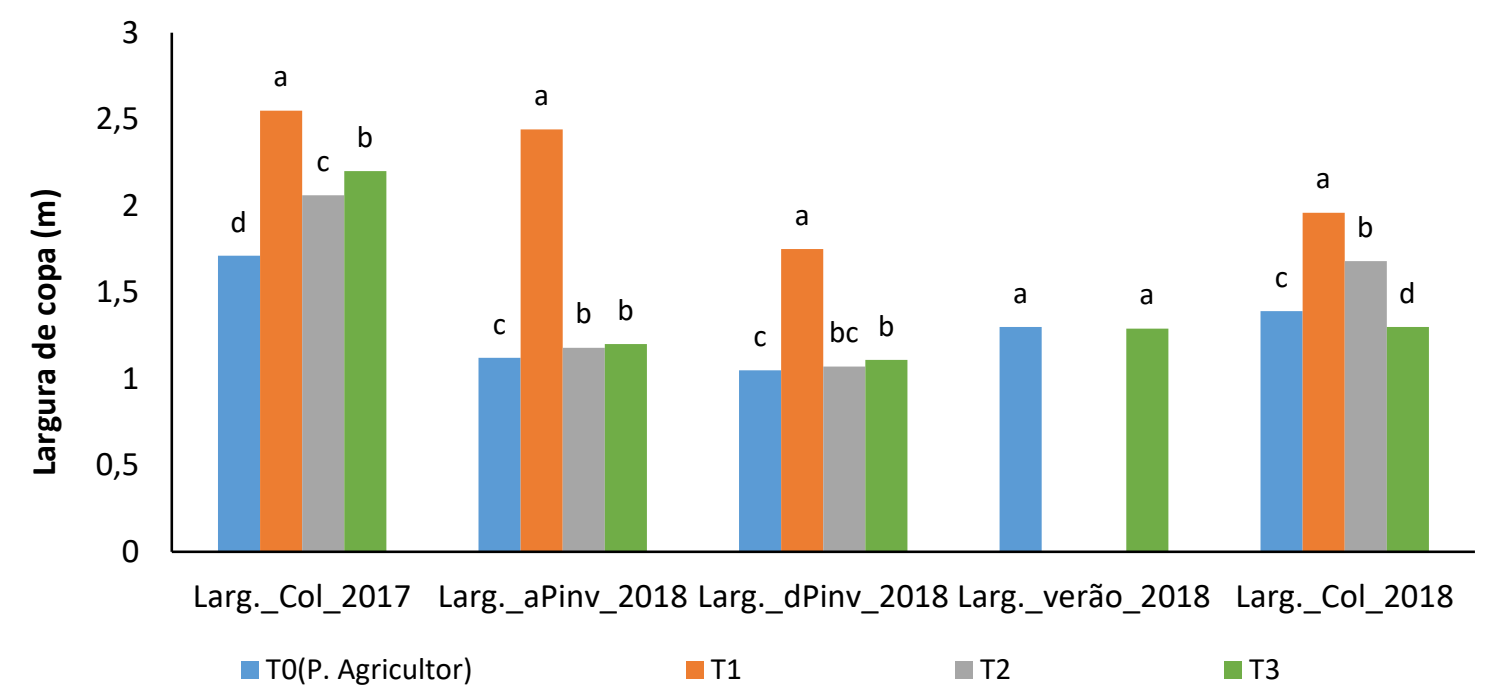

Colunas acompanhadas de letras diferentes diferem significativamente entre si, segundo o teste de separação de médias de Duncan $(\mathrm{P} \leq 0,05)$

Figura 7. Largura média da copa das árvores após a poda, por tratamento, em cada um dos anos. 


\section{CONGRESO IBÉRICO DE AGROINGENIERÍA \\ X CONGRESSO IBÉRICO DE AGROENGENHARIA \\ 3 - 6 septiembre 2019, Huesca - España}

Antes da poda de inverno de 2018 verificaram-se diferenças significativas $(\mathrm{P}<0.05)$ entre os tratamentos, tendo o tratamento $\mathrm{T} 1$ registado uma largura de copa significativamente superior $(\mathrm{P} \leq 0.05)$ aos restantes tratamentos, os quais revelaram uma grande uniformidade. Tal deve ao facto de nestes tratamentos se ter realizado uma intervenção de poda mecânica pós-colheita.

Após a poda de inverno de 2018 a situação manteve-se, apesar da redução da largura de copa no tratamento T1. A intervenção de poda manual realizada neste tratamento consistiu em desramações, eliminando os ramos mais vigorosos para a entrelinha. Tal não foi suficiente para que a largura de copa ficasse a um nível idêntico à dos outros tratamentos.

Não se verificaram diferenças significativas $(P>0.1)$ na largura de copa após os cortes de verão visto que o posicionamento da barra de corte foi idêntico, de modo a eliminar apenas os lançamentos para a entrelinha. O sistema de autoguiamento controlado por GPS montado no tractor com a máquina de podar contribuiu para a uniformidade dos cortes efectuados.

O trabalho realizado durante o ano de 2018 permitiu diminuir a largura de copa, comparativamente ao que se registou em 2017, tendo-se verificado diferenças significativas entre os tratamentos $(\mathrm{P}<0.05)$.

Conforme seria de esperar o tratamento T1 registou a maior largura de copa, a qual foi significativamente $(\mathrm{P} \leq 0.05)$ superior à dos restantes tratamentos, que diferiram entre si.

$\mathrm{O}$ tratamento T2 registou uma largura de copa significativamente $(\mathrm{P} \leq 0.05)$ superior aos tratamentos onde se realizaram podas de verão (T0 e T3). A poda de verão efectuada em Julho permite que as árvores à colheita tenham uma largura significativamente inferior à registada no tratamento podado em Junho (T0). Tal mostra que a resposta vegetativa ao corte de julho será menor do que ao corte de junho. De referir que podem ocorrer perdas de amêndoa para o solo com estes cortes, principalmente se existirem ramos excessivamente salientes.

\subsection{Capacidade de trabalho}

Na figura 8 mostra-se a capacidade de trabalho na intervenção de poda manual por tratamento, em cada um dos anos.

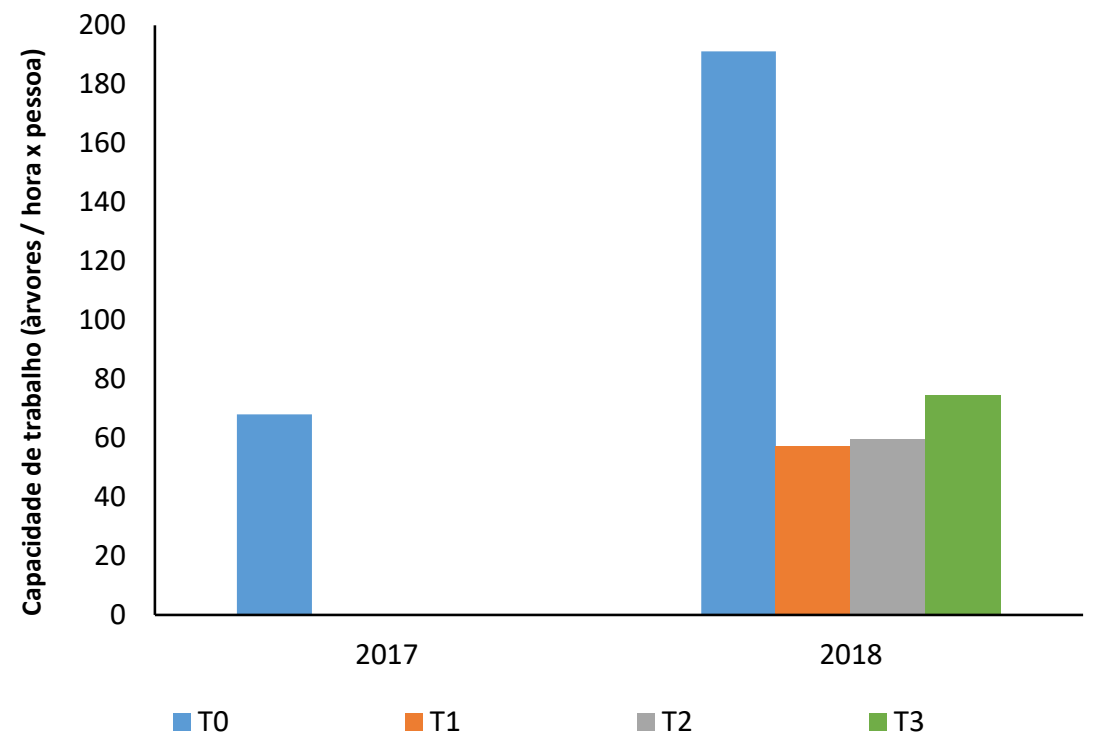

Figura 8 - Capacidade de trabalho na execução da poda manual, por tratamento, em cada um dos anos.

A poda manual efectuada em 2017 no tratamento T0 contribuiu para que no ano seguinte (2018) o tempo gasto na poda manual fosse consideravelmente mais baixo. 


\section{CONGRESO IBÉRICO DE AGROINGENIERÍA \\ X CONGRESSO IBÉRICO DE AGROENGENHARIA \\ 3 - 6 septiembre 2019, Huesca - España}

Não se verificaram diferenças consideráveis no tempo despendido na poda manual entre os tratamentos T1, T2 e T3 visto que estas modalidades estiveram até 2018 sem serem submetidas a intervenções de poda manual (Figura 4). A intervenção de poda de 2018 foi similar em qualquer destes tratamentos, tendo-se eliminado ramos excessivamente lenhificados que estavam a competir com o eixo central inicialmente definido. Este tipo de intervenção foi substancialmente diferente da executada no tratamento T0, que serviu para eliminar alguns ramos que tendiam crescer para a entrelinha.

Na figura 9 mostra-se a capacidade de trabalho da máquina de podar de discos por tratamento em função da época de realização das intervenções de poda. A capacidade de trabalho da máquina de podar de discos no tratamento T0 em 2017 resulta de apenas se ter efectuado "topping", para o qual apenas é necessária uma passagem de máquina por cada linha de árvores. No caso das restantes intervenções, foram sempre efectuadas 3 passagens de máquina por cada linha de árvores, bem como as respectivas manobras de cabeceira. Tal como seria de esperar não se registaram diferenças assinaláveis na capacidade de trabalho na execução dos cortes de verão, independentemente de serem realizados após a colheita (2017) ou antes da colheita (tratamentos T0 e T3, em 2018).

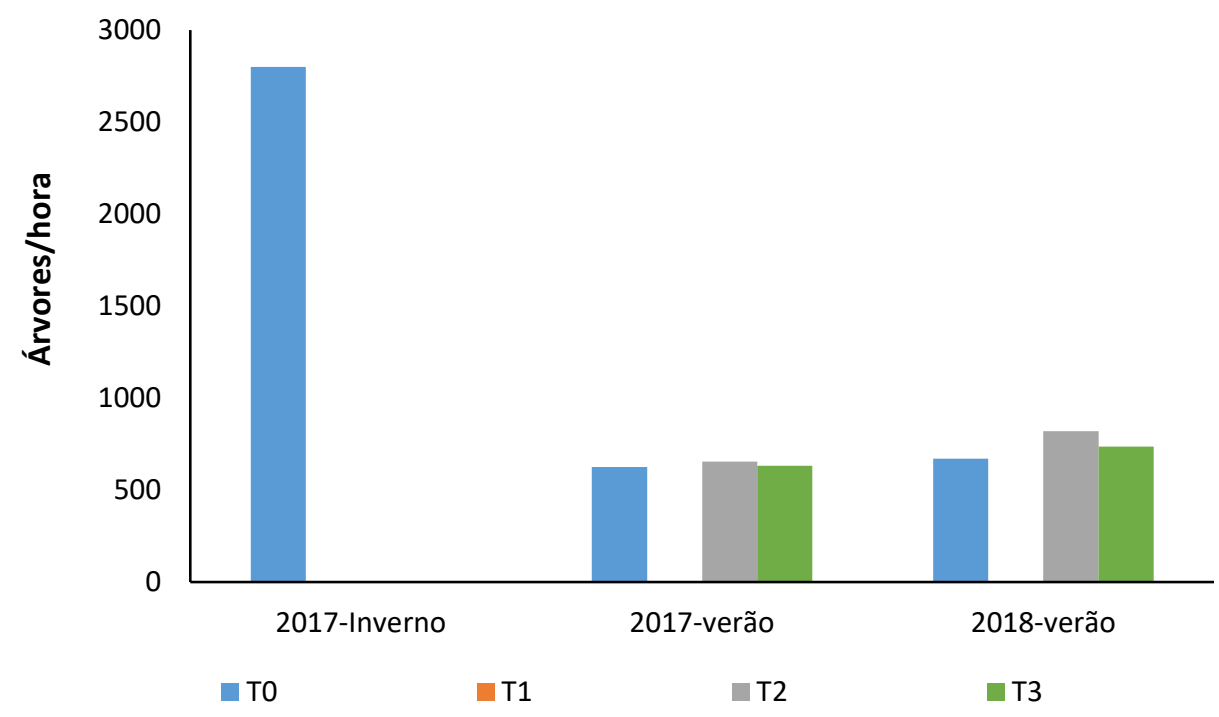

Figura 9 - Capacidade de trabalho na execução da poda mecânica, por tratamento, em cada um dos anos

\subsection{Produção de amêndoa}

Na figura 10 mostra-se a produção de amêndoa por árvore obtida por cada tratamento em 2017 e 2018, bem como a produção acumulada nos dois anos. Em 2017 não se verificaram diferenças significativas entre os tratamentos $(\mathrm{P}>0.1)$, com os tratamentos $\mathrm{T} 1$ e $\mathrm{T} 2$ a registarem a produção mais baixa.

Em 2018 verificaram-se diferenças significativas $(\mathrm{P}<0.05)$ entre os tratamentos na produção de amêndoa. Os tratamentos T1 e T2 produziram significativamente $(\mathrm{P} \leq 0.05)$ mais do que os tratamentos T0 e T3. Tal revela alguma tendência para a alternância de produção visto que os tratamentos que produziram mais em 2017 tiveram um decréscimo de produção em 2018.

Em termos de produção de amêndoa acumulada não se verificaram diferenças significativas entre os tratamentos $(\mathrm{P}>0.1)$, com os tratamentos $\mathrm{T} 1 \mathrm{e} \mathrm{T} 2$ a registarem os valores mais elevados. 


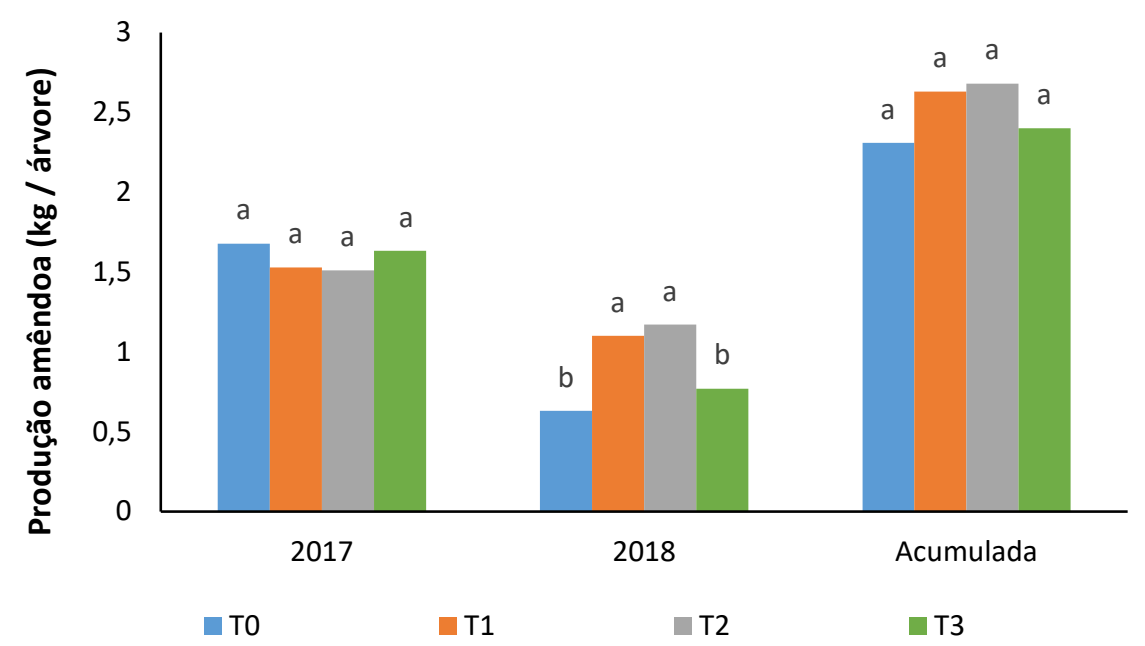

Colunas acompanhadas de letras diferentes diferem significativamente entre si, segundo o teste de separação de médias de Duncan $(\mathrm{P} \leq 0,05)$

Figura 10 - Produção média de amêndoa por árvore (kg matéria seca) e por tratamento.

\subsection{Eficiência de recolha}

Na figura 11 mostram-se as perdas de amêndoa para o solo por árvore durante a colheita obtidas em cada tratamento em 2017 e em 2018.

Em 2017 não se verificaram diferenças significativas entre os tratamentos $(P>0.1)$, com os tratamentos $\mathrm{T} 1$ e $\mathrm{T} 3$ a registarem as maiores perdas.

A ausência de intervenções de poda no tratamento T1 leva a que as árvores cresçam livremente revestindo-se de ramos longos e flexíveis, que permitiram a passagem da máquina de colheita sem que se verificasse a ocorrência de danos consideráveis. Naturalmente que uma parte da produção se perdeu para o solo.

A menor percentagem de perdas verificou-se no tratamento T0, o qual estará associado á menor largura de copa e ao facto dos ramos da parte superior da copa não terem produção por serem fundamentalmente ramos ladrões emitidos após o "topping" de inverno realizado neste ano.

A ocorrência de maiores perdas no tratamento $\mathrm{T} 3$ em relação ao tratamento $\mathrm{T} 2$ poderá deverse à maior largura de copa das árvores do tratamento T3.

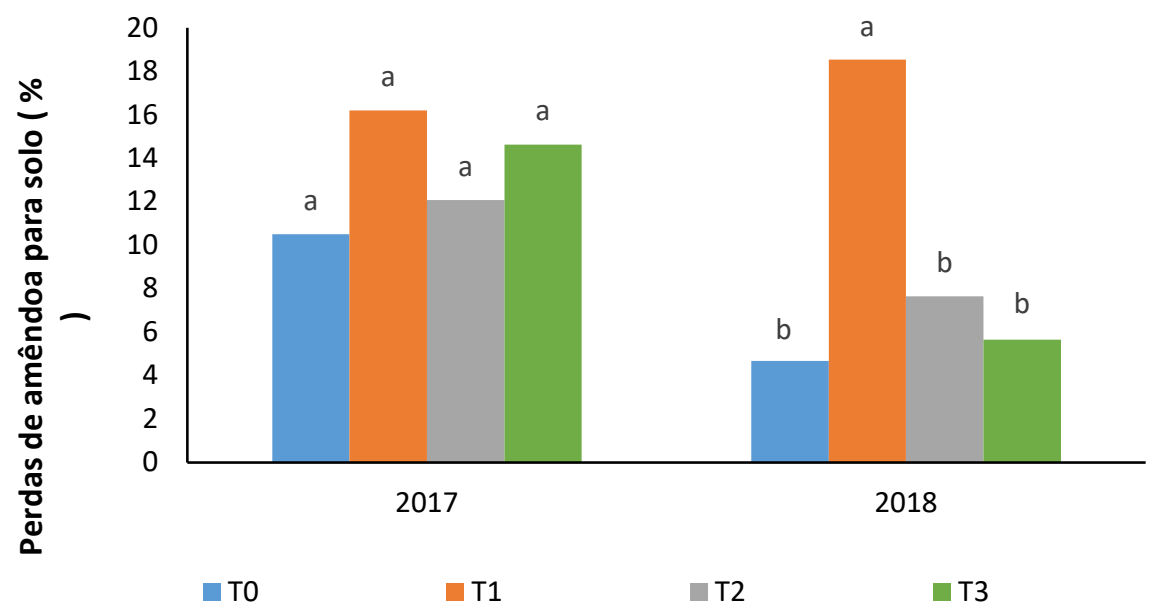

Colunas acompanhadas de letras diferentes diferem significativamente entre si, segundo o teste de separação de médias de Duncan ( $\mathrm{P} \leq 0,05)$

Figura 11. Perdas de amêndoa para o solo por árvore (kg matéria seca) e por tratamento. 


\section{CONGRESO IBÉRICO DE AGROINGENIERÍA \\ X CONGRESSO IBÉRICO DE AGROENGENHARIA \\ 3 - 6 septiembre 2019, Huesca - España}

Em 2018 verificaram-se diferenças significativas $(\mathrm{P}<0.05)$ entre os tratamentos nas perdas de amêndoa para o solo, com o tratamento T1 a registar perdas significativamente superiores $(\mathrm{P} \leq 0.05)$ aos restantes tratamentos. Neste ano a maior parte das perdas deste tratamento tiveram origem nos ramos altos que excediam a altura da unidade de colheita da máquina automotriz (Figura 12). Estes ramos suportavam parte da produção, pelo que o impacto com a estrutura da máquina de colheita e a sua flexão levava a que as amêndoas aí situadas caíssem para o solo. De referir que nos restantes tratamentos as intervenções de poda realizadas em 2018 para controlo da dimensão das árvores permitiram reduzir a percentagem de perdas de amêndoa para o solo.

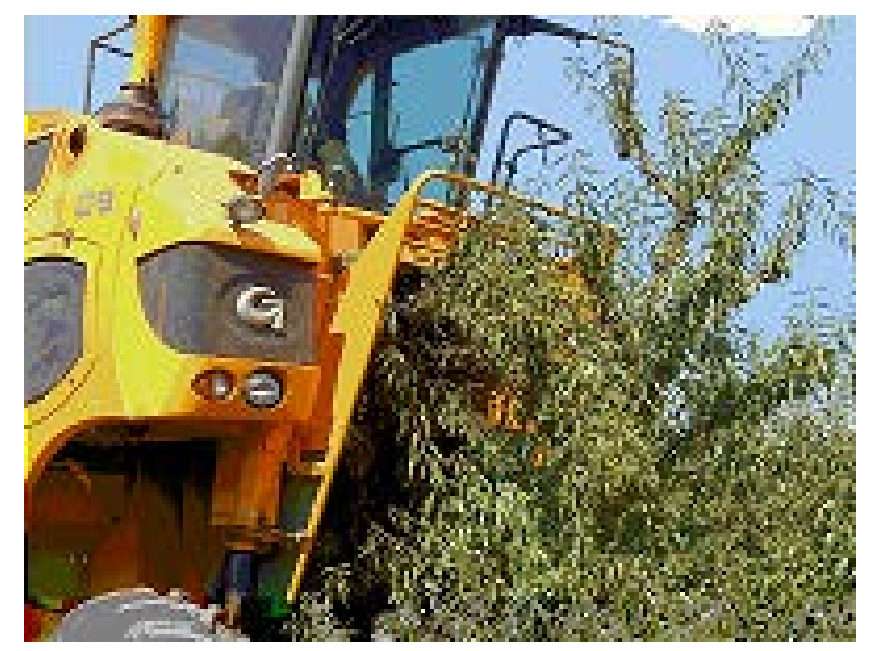

Figura 12 - Ramos com amêndoa acima máquina colheita

\subsection{Produção recolhida}

Na figura 13 mostra-se a massa de amêndoa recolhida por árvore em cada tratamento, em 2017 e em 2018.

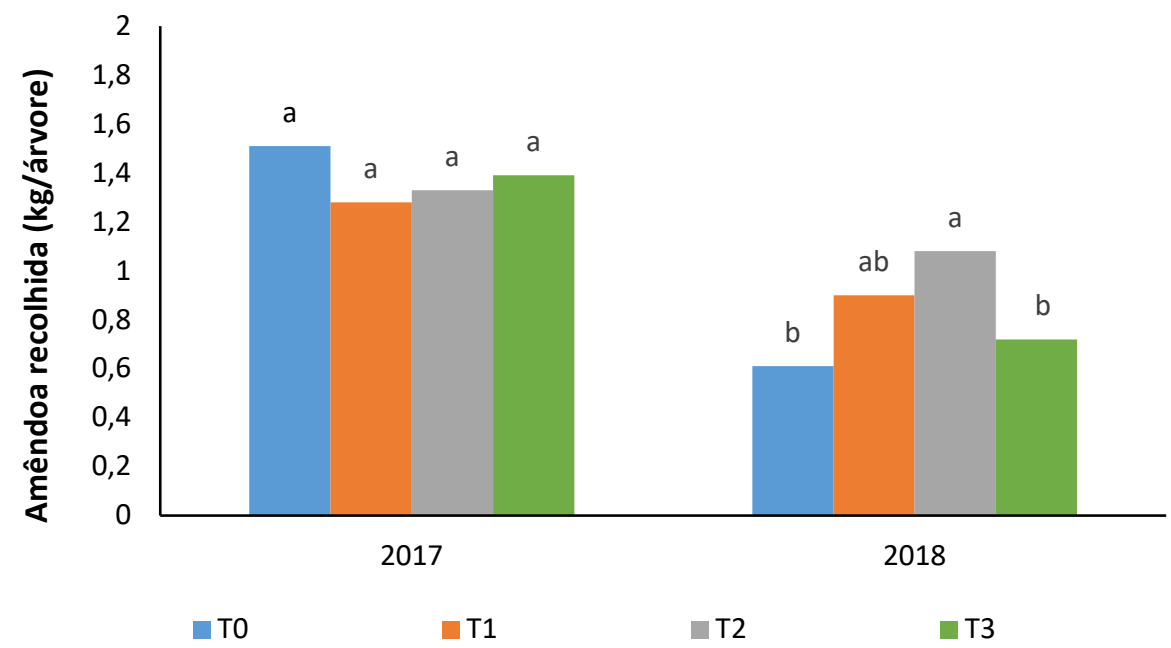

Colunas acompanhadas de letras diferentes diferem significativamente entre si, segundo o teste de separação de médias de Duncan $(\mathrm{P} \leq 0,05)$

Figura 13 - Massa de amêndoa recolhida por árvore (kg matéria seca), por tratamento.

Em 2017 não se verificaram diferenças significativas entre os tratamentos ( $P>0.1)$, tal como se tinha registado em termos de produção de amêndoa e de eficiência de recolha. 


\section{CONGRESO IBÉRICO DE AGROINGENIERÍA \\ X CONGRESSO IBÉRICO DE AGROENGENHARIA \\ 3 - 6 septiembre 2019, Huesca - España}

Em 2018 verificaram-se diferenças significativas $(\mathrm{P}<0.05)$ entre os tratamentos na massa de amêndoa recolhida por árvore, com o tratamento $\mathrm{T} 2$ a diferir significativamente $(\mathrm{P} \leq 0.05)$ dos tratamentos T0 e T3. Embora o tratamento T1 tenha registado maior percentagem de perdas de amêndoa para o solo (Figura 11), o maior nível produtivo deste tratamento foi suficiente para assegurar a recolha de uma massa de amêndoa superior à registada nos tratamentos T0 e T3.

\subsection{Custos de poda}

Tendo por base as capacidades de trabalho indicadas nas figuras 8 e 9 e a produção recolhida (Figura 13) calculou-se o custo da poda de 2017 e 2018, por kg de amêndoa recolhida em cada um dos tratamentos. Neste cálculo considerou-se que a máquina de podar de discos custa 70 Euros/hora em regime de prestação de serviços e que a poda manual em prestação de serviços custa 70 euros/dia e por pessoa, incluindo a motosserra e o combustível.

Na figura 14 mostra-se a variação do custo da poda pela amêndoa recolhida, em cada um dos tratamentos. O maior número de intervenções de poda manual do tratamento T0 (poda do agricultor) originou um acréscimo de custo comparativamente aos outros tratamentos. Tal foi mais evidente no caso do tratamento T1, no qual apenas houve uma intervenção de poda manual. $\mathrm{O}$ maior custo dos tratamentos T2 e T3 relativamente ao tratamento T1 deve-se às intervenções de poda mecânica realizadas. Será conveniente assegurar a continuidade deste ensaio de modo a perspectivar os custos de poda durante um maior período de tempo.

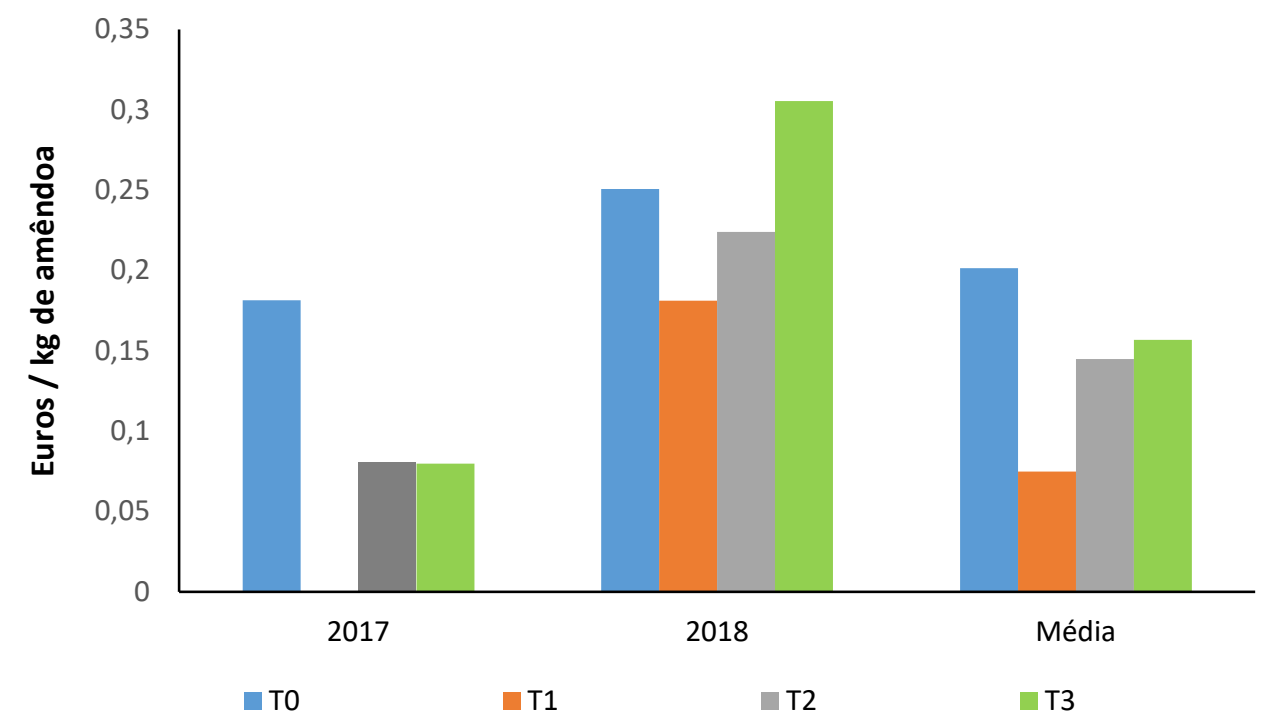

Figura 14. Custo da poda por quilograma de amêndoa recolhida

\section{Conclusões}

Os resultados obtidos vêm confirmar a necessidade de adequar a dimensão das árvores à máquina de colheita para minimizar as perdas de amêndoa para o solo.

A utilização da máquina de podar de discos permite realizar esse trabalho rapidamente conforme seria de esperar. As intervenções em verde parecem ser uma solução a considerar nomeadamente no controlo da altura das árvores, visto que a emissão de novos lançamentos tende a ser menor.

Será necessário dar continuidade a estes trabalhos durante um maior período para avaliar o efeito na produção de amêndoa, na eficiência de recolha da máquina de colheita e nos custos de poda. 
X CONGRESO IBÉRICO DE AGROINGENIERÍA

X CONGRESSO IBÉRICO DE AGROENGENHARIA

3 - 6 septiembre 2019, Huesca - España

\section{Agradecimentos}

Este trabalho só foi possível graças à disponibilização de todos os meios pela Torre das Figueiras Sociedade Agrícola Lda.

\section{Referências}

1. Cardoso, J. 1965. Os solos de Portugal a Sul do rio Tejo. Direção Geral dos Serviços Agrí́colas, Lisboa.

2. Peça, J.O., Dias, A.B., Pinheiro, A.C., Santos, L., Morais, N., Pereira, A.G., Reynolds de Souza, D. 2002. Mechanical pruning of olive trees as an alternative to manual pruning. p. 295-299. Acta Hort. 586, 295299.

3. Torrents, J. 2015. Estado actual del cultivo superintensivo del almendro, Actas Simposio Nacional de Almendro y otros Frutos secos, Lérida, Espanha 24 Set. p.29-43. 